\title{
Influencing factors on mental health of the elderly under Network Environment
}

\author{
Ping $\mathrm{Hu}^{1, \mathrm{a}}$, Bin Gong ${ }^{1, \mathrm{~b}, *}$ and Wenli Fan², c \\ ${ }^{1}$ Chengdu Medical College, School of Humanities and Information Management, Chengdu 610500, \\ China; \\ 2 School of Electrical Engineering, Southwest Jiaotong University, Chengdu 610031, China. \\ awhoopingfwl@163.com, b2936119304@qq.com, c317836798@qq.com
}

Keywords: The elderly, mental health, network environment.

\begin{abstract}
In order to explore the factors that affect the mental health of the elderly under the network environment, we take the182 residents of 60 and over 60 years old people as the main objects, who are in Zhengyin village, Xindu district, Chengdu city. After a questionnaire survey and data acquisition, a database is built with Excel software and is analyzed by SPSS22.0 statistical software. The results show that the telephone usage has the most significant impact on the mental health of the elderly, followed by the Internet entertainment, social software, reading online news, and watching online videos. Finally, some suggestions are put forward to improve the mental health of the elderly according to these factors.
\end{abstract}

\section{Introduction}

Chinese population aged 60 and more has accounted for 230 million, accounting for $16.7 \%$ of the total population till 2016. At present, China has entered an aging society, so improving the mental health of the elderly is of great significance. Ref.[1] adopted the Logit and the fixed effect model to analyze and validate the interaction between social participation and self-rated health among the elderly in the mainland of China based on the Chinese Longitudinal Healthy Longevity (CLHLS) ${ }^{[1]}$. Ref.[2] found that there were great differences in mental health status among the elderly groups with different household registrations, ages and family relations based on the field survey data ${ }^{[2]}$. Ref.[3] investigated the effects of demographic variables, physical exercises and other factors on physical, psychological and social health scores of the elderly people in Nanjing city ${ }^{[3]}$. Ref.[4] discussed the factors affecting the mental health of the elderly from the three aspects of physical, psychological and social resources ${ }^{[4]}$. Ref.[5] explored the influencing factors of health information seeking behavior among the elderly in the network environment in China ${ }^{[5]}$. In this paper, we focus on the factors affecting the mental health of the elderly in the Internet environment.

\section{Data Source}

This survey uses an anonymous questionnaire in Xindu district Chengdu city, and all objects were or more than 60 years old. the designed problems are easy to answer, so the elderly can show the objective facts of themselves. We will give some suggestions to the elderly after finding the influencing factors affecting the mental health of the elderly.

\subsection{Basic Data of Main Objects.}

We conducted the survey only in Xindu district, Chengdu city, and all objects were or more than 60 years old. We issued 200 and received 187 questionnaires, and the recovery rate was 93.5\%. After eliminating invalid questionnaires, we got 182 copies of valid ones and the questionnaire response rate was 97.3\%, where there are 105 male and 77 female respectively. Moreover, there are 93 old people aged 60-64, 57 people aged 65-69 years old, 23 people aged 70-74 years old, 9 people aged 75 and more. In addition, there are 161 people married, 7 people divorced and 3 people widowed. The 
questionnaire was designed mainly from the following aspects: telephone usage, reading online news, watching online videos, etc.

\subsection{Data Statistics.}

The results of the surveyed mental health level of the old people showed that 14 old people are in low mental health status, among whom 9 were male and 5 were female. There are 26 old people with lower mental health, among whom 19 are male, 7 are female, and the corresponding numbers for the old people in the middle class mental health, the higher and the highest mental health are [54, 32, 22], $[61,32,29]$ and $[27,13,14]$ respectively.

According to the using rates of the telephone, the reading online news, the watching online videos, Internet entertainment and social software, the mental health levels of the elderly are shown in Table $1 \sim$ Table 5 respectively.

Table 1. Mental health level of the elderly with different telephone usage rates

\begin{tabular}{cccccc}
\hline Telephone Using & \multicolumn{5}{c}{ Mental Health Level of the Elderly } \\
\cline { 2 - 6 } Rates & Lowest & Lower & Middle & Higher & Highest \\
\hline Low & $16.7 \%$ & $33.3 \%$ & $33.3 \%$ & $16.7 \%$ & $0.0 \%$ \\
Middle & $12.2 \%$ & $21.9 \%$ & $36.6 \%$ & $24.4 \%$ & $4.9 \%$ \\
High & $5.9 \%$ & $11.1 \%$ & $27.4 \%$ & $37.1 \%$ & $18.5 \%$ \\
\hline
\end{tabular}

Table 2. Mental health level of the elderly with different reading online news rates

\begin{tabular}{cccccc}
\hline Reading Online News & \multicolumn{5}{c}{ Mental Health Level of the Elderly } \\
\cline { 2 - 6 } Rates & Lowest & Lower & Middle & Higher & Highest \\
\hline Low & $16.2 \%$ & $13.5 \%$ & $46.0 \%$ & $13.5 \%$ & $10.8 \%$ \\
Middle & $5.4 \%$ & $16.2 \%$ & $27.1 \%$ & $37.8 \%$ & $13.5 \%$ \\
High & $5.6 \%$ & $12.7 \%$ & $24.0 \%$ & $39.4 \%$ & $18.3 \%$ \\
\hline
\end{tabular}

Table 3. Mental health level of the elderly with different watching online videos rates

\begin{tabular}{cccccc}
\hline Watching Online & \multicolumn{5}{c}{ Mental Health Level of the Elderly } \\
\cline { 2 - 6 } Videos Rates & Lowest & Lower & Middle & Higher & Highest \\
\hline Low & $7.7 \%$ & $15.4 \%$ & $30.8 \%$ & $38.4 \%$ & $7.7 \%$ \\
Middle & $8.1 \%$ & $16.3 \%$ & $31.4 \%$ & $34.9 \%$ & $9.3 \%$ \\
High & $7.2 \%$ & $12.1 \%$ & $27.7 \%$ & $31.3 \%$ & $21.7 \%$ \\
\hline
\end{tabular}

Table 4. Mental health level of the elderly with different Internet entertainment rates

\begin{tabular}{cccccc}
\hline Internet Entertainment & \multicolumn{5}{c}{ Mental Health Level of the Elderly } \\
\cline { 2 - 6 } Using Rates & Lowest & Lower & Middle & Higher & Highest \\
\hline Low & $12.7 \%$ & $24.0 \%$ & $39.2 \%$ & $19.0 \%$ & $5.1 \%$ \\
Middle & $4.7 \%$ & $8.1 \%$ & $23.3 \%$ & $46.5 \%$ & $17.4 \%$ \\
High & $0.0 \%$ & $0.0 \%$ & $17.6 \%$ & $35.3 \%$ & $47.1 \%$ \\
\hline
\end{tabular}

Table 5. Mental health level of the elderly with different social software using rates

\begin{tabular}{cccccc}
\hline Social Software & \multicolumn{5}{c}{ Mental Health Level of the Elderly } \\
\cline { 2 - 6 } Using Rates & Lowest & Lower & Middle & Higher & Highest \\
\hline Low & $29.6 \%$ & $37.1 \%$ & $18.5 \%$ & $7.4 \%$ & $7.4 \%$ \\
Middle & $6.8 \%$ & $15.9 \%$ & $31.8 \%$ & $35.3 \%$ & $10.2 \%$ \\
High & $0.0 \%$ & $3.0 \%$ & $31.3 \%$ & $41.8 \%$ & $23.9 \%$ \\
\hline
\end{tabular}

\section{Data analysis}

According to the statistical data of the questionnaire, $22 \%$ of the old people who received questionnaires had different levels of mental health problems. Among them, 7.7\% of the elderly had serious mental health problems. Among the elderly surveyed, the mental health level of the female 
elderly is higher than that of the male. With the aging of the elderly, the mental health of the elderly is on the downward trend. Table 6 shows the regression analysis between the mental health level of the elderly and the Internet using.

Table 6. Regression analysis between the mental health level and the Internet using

\begin{tabular}{|c|c|c|c|c|c|}
\hline $\begin{array}{l}\text { Dependent } \\
\text { Variable }\end{array}$ & Independent Variable & $\begin{array}{c}\mathrm{R}^{2} \text { (After } \\
\text { Adjustment) }\end{array}$ & $\mathrm{F}$ & Beta & $\mathrm{t}$ \\
\hline \multirow{5}{*}{$\begin{array}{l}\text { Mental Health } \\
\text { Level }\end{array}$} & Telephone Using Rate & 0.999 & $2268.750 * *$ & 1.000 & $47.631 * *$ \\
\hline & Reading Online News Rates & 0.888 & $16.922^{* *}$ & 0.972 & $4.114^{* *}$ \\
\hline & Watching Online Videos Rates & 0.028 & $1.058 * *$ & 0.717 & $1.028 * *$ \\
\hline & $\begin{array}{c}\text { Internet Entertainment Using } \\
\text { Rates }\end{array}$ & 0.941 & $32.795 * *$ & 0.985 & $5.727 * *$ \\
\hline & Social Software Using Rates & 0.907 & $20.615 * *$ & 0.977 & $4.540 * *$ \\
\hline
\end{tabular}

As can be seen from Table 6, the mental health levels of the elderly differ from each other with the different utilization of the networks. Obviously, the telephone using rate (Beta=1.000) has the greatest impact on the mental health of the elderly. The higher the telephone using rate is, the higher the mental health level of the elderly is. The influence of Internet entertainment rate (Beta=0.985) on the mental health of the elderly is the second, and the higher the frequency of online entertainment, the higher the mental health level of the elderly is. The third is the use of social software (Beta=0.977). The higher the frequency of social software use, the higher the mental health level. Next is the reading online news, and the last is the watching online videos. Similarly, if the elderly often read online news and watch online videos, they will have higher mental health levels.

In addition, according to the statistical data of the questionnaire, $22 \%$ of the old people who received questionnaires have different mental health problems. Among them, $7.7 \%$ of the elderly had serious mental health problems.

Through the results of the questionnaire survey, we also found that the state of the human body is another big factor affecting the mental health level of the elderly. The reason for this is that most older people are the backbones of the families when they were young, but this state gradually disappears as the body declines and the income or housework capacity decreases. In addition, the elderly people's marital status also caused a relatively large impact on the level of mental health, and mental health level of the married elderly people generally higher than that of the divorced, widowed and childless people. The level of mental health for the elderly widows is the lowest.

\section{Conclusion}

In this paper, we have investigated the factors that affect the mental health of the elderly under the network environment through a questionnaire survey and data acquisition. The results have shown that the phone using is the most significant factor, especially the effect on the mental health of the aged people. Next is the Internet entertainment, which affects the elderly with relatively smaller ages seriously. The third is the use of social software, which has a significant influence on the female old people. And then is the reading online news and the watching online videos.

Therefore, we can take care of the elderly from the following aspects. Firstly, concern more about the elderly with poor health and the male old people. Secondly, focus more on the elderly alone. Thirdly, teaching old people to use telephone and increase the frequency of Internet entertainment among the elderly. Fourthly, let older people develop the habit of using social software and reading online news.References are cited in the text just by square brackets [1]. (If square brackets are not available, slashes may be used instead, e.g. /2/.) Two or more references at a time may be put in one set of brackets $[3,4]$. The references are to be numbered in the order in which they are cited in the text and are to be listed at the end of the contribution under a heading References, see our example below. 


\section{References}

[1]. Lu Jiehua, Li Yue, Zheng Bing. The Relationship between Self-Reported Health and Social Participation of Chinese Elderly: Evidence from CLHLS Survey. Population Research. Vol. 41 (2017) No. 1, p. 15-25.

[2]. Luan Wenjing, Yang Fan, Chuan Hongli, et al. The Study on the Psychological Health Status of Old People in China and Its Influencing Factors. Journal of Northwest University( Philosophy and Social Sciences Edition). Vol. 42 (2012) No. 3, p. 75-83.

[3]. Gao Liang, Wang Jiahong, Wand Lihua. The Influence of Physical, Phychological and Social Health for the Elderly Score in Nanjing City. Journal of Sports and Science. Vol. 37 (2016) No. 4, p. 107-114.

[4]. Beverly L. Roberts, Ruth D, Marie H. Physical, Psychological, and Social Resources as Moderators of the Relationship of Stress to Mental Health of the Very Old. Journal of Gerontology. (1994) No. 1, p. S35-S43.

[5]. Zhu Shubei, Deng Xiaozhao. Study on Influence Factors of Older Adults'Online Health Information Seeking. Library and Information Services. Vol. 59 (2015) No. 5, p. 60-67. 